\title{
Identity Negotiation in Relation to Context of Communication
}

\author{
Ying Huang \\ School of Foreign Languages \& Literature, Yunnan Normal University, Kunming, China \\ Email: nancyhuang1207@yahoo.com.cn
}

\begin{abstract}
This paper explores how tour guides negotiate their identities in a multiple context of communication. The context is characterised as professional, commercialized and Chinese. The discussion is based on an investigation into the communication between Chinese tour guides and their international tourists. Findings indicate that to communicate effectively and appropriately in these contexts, tour guides have to actively construct meaning through a negotiated balance of content, identity and relationship.
\end{abstract}

Index Terms - identity, context of communication, tour guides, intercultural communication

\section{INTRODUCTION}

In intercultural communication, perceptions and strategies of communication, to some degree, are determined by the context of communication. In terms of context, there are two perspectives: a specific context of situation and a larger context of culture. The latter includes tribal economics, social organization, kinship patterns, fertility rites, seasonal rhythms, concepts of time and space. It is a more abstract, and not easy to change (Kramsch, 2008, p. 26).

With the development of globalization, communication between people from different cultures is increasing every day. People travel cross-culturally for different purposes: education, tourism, business, leisure and so on. Among them, tourism has attracted quite a large number of people. As an important component in tourism industry, tour guides' service quality means quite a lot to the experience of the tourists.

In China, foreign language speaking tour guides are also called international tour guides. They are employed by travel agencies which are authorised by China National Tourism Administration (CNTA) for receiving foreign tourists. International tour guides provide service to people from a country other than China. Their service is different from the service to domestic tourists because they will encounter both language and cultural barriers (Cai \& Woods, 1993). When international tourists visit China, they bring with them different cultural baggage filled with cultural norms, behaviours, value systems, and communication styles. These differences may lead to misunderstanding, miscommunication or even conflicts. But what strategies do tour guides employ to overcome these difficulties, to solve problems and to sooth conflicts? In front of conflicts, how do tour guides negotiate their identities? To answer these questions, a research was conducted in Yunnan Province of China.

Ting-Toomey's mindful intercultural communication model was chosen as the starting point to build a possible theoretical framework. In addition, this study take into account the perspective of tourism as the context for understanding the essence of tour guides' communication and the strategies they employ in their interaction with international tourists, and how they negotiate their identities in the specialized context.

\section{LITERATURE REVIEW}

In Ting-Toomey's (1999, p.28) identity negotiation perspective, identity means "the reflective self-conception or self-image that we each derive from our cultural, ethnic, and gender socialisation processes. It is acquired via our interaction with others in particular situations". According to this definition, identity is the reflective view of a person's self, and this reflection is relevant to his or her culture. Identity meaning is relevant to questions such as "Who am I and who are you?"

Ting-Toomey differentiates two groups of identities: primary and situational identity. The primary identities include cultural identity, ethnic identity, gender identity and personal identity. Situational identity includes role identity, relational identity, facework identity and symbolic interaction identity. The four situational identities change from situation to situation. She argues that these two groups of identities have interactive relations, and they play a critical role in the mindful intercultural communication process. There is a mutual influence between the two groups, and there is also an interactive and relevant relationship between these eight identities. For example, a threat to ones' cultural identity can be perceived as a threat to the personal self-esteem level (Ting-Toomey, 1999, p.30). Through competent or incompetent communication skills, situational identities can influence the way people view themselves, either negatively or positively. Individuals have these identities either consciously or subconsciously. What identity or identities they make salient depends on the particular situation they are in. When this person is in his or her own culture, 
usually his or her cultural identity is not as important as when he or she is interacting with an out-group person (Gudykunst, 1994).

Ting-Toomey argues that individuals compare their salient identity groups with others for they need to keep positive social identities. There are three bases for their comparison: lateral comparison (essentially the same level), downward level comparison (less powerful groups), and upward comparison (more powerful groups). Individuals try to maintain distance from their in-group by de-emphasising the importance of their social identities and maximising the importance of their personal identities. This happens when there is negative comparison. On the other hand, they enhance their personal identities by allying themselves with members of high-status groups (p151). Or when group boundaries are permeable, they switch group membership. From the social identity theory perspective, people have in-group favouritism and out-group differentiation (p147). There are some conditions under which people's cultural or ethnic identities unconsciously become salient, for example, when they are facing emotional vulnerability, and when their membership identity is negatively or positively stigmatised.

Personal identity includes any unique attributes that people associate with their individual self in comparison to those of others. Individuals develop distinctive personal identities due to their unique life histories, experiences, and personal traits, and via their observations of role models around them and their own drives and reinventions. Ting-Toomey emphasises in her theory that culture plays an influential role in personal identity development. This is because the perception of a "unique self" (p35) is developed via their observation of role models around them. So the context an individual is in plays an important role in developing this perception. Personal identity has two facets: actual personal identity and desired personal identity. Any communicator has a desired identity which is the attribute he or she prefers. To reach this desired identity, communicators need the feeling of being understood, respected and supported. The desired identity is more important in the identity negotiation approach than the actual identity is.

Role and role identity are fundamental elements in understanding tour guides' strategies in intercultural communication. According to Ting-Toomey (1999, p36), role is "a set of expected behaviours and the values associated with them that a culture or ethnic group defines as proper or acceptable". It is more situation-bound because it is valued and judged by people with varied expectations. These judgments and expectations are influenced by personal, situational and cultural variables. This applies to tour guides who might have different perceptions on their role identity, as well as the expected role identities of other people.

Everybody in a society has within himself or herself the varied identities. What distinguishes one person from another is what identity or identities they emphasise or make salient at a certain time. The varied and complicated roles of international tour guides also mean they have different identities, or they have to make some identities salient in a specific situation. They have professional identities, national/ethnic identity, cultural identity, and personal identity. Their cultural identities might be more prominent in this situation than when they are interacting with their in-group peers (Gudykunst, 1994). The question is what identity do they present at a certain time? Who do they represent, themselves, the company or the country?

Culture is an important element in developing identities, especially personal identities. Tour guides' pre-existing perception and images of themselves come not only from schooling but also from word of mouth, from mass media, from their interaction with other people, and from other social relations. Their perception of professional identities will be changed after they enter the profession through their experience, their observation, and communication. How do tour guides balance or negotiate these identities, especially when there are conflicts among them? If tour guides are not able to maintain a balanced identity, their communication with their international tourists is unlikely to be considered appropriate or effective, that is, successful, by tourists.

\section{RESEARCH METHODS}

To find out how Chinese tour guides negotiate or balance their identities, and how they have effective or appropriate communication with their international tourists, an investigation was carried out in Yunnan Province of China. Yunnan is located in the southwest of China. It has become one of the most attractive tourist destinations due to its picturesque landscape and colorful ethnic culture. In 1998, Yunnan received 760,000 overseas tourists, and 10 years later, in 2007, the number of international tourists grew to 4.58 million. And now the provincial government is making efforts to develop its unique tourism resources under the globalization environment.

The research adopted a qualitative research methodology from a constructivist perspective. This research started from an assumption that tour guides' individual agency is a key factor contributing to different perceptions of the goals and strategies of intercultural communication. It employed Ting-Toomey's model of mindful intercultural communication through the construction of meaning by understanding and interpretation. To achieve this goal demands communicative skills that help enhance mutual understanding, repair relationships and create "shared meanings". Culture and context are also crucial, but the fundamental process is generated through mindful agency.

Nineteen professional English-speaking tour guides and 5 tourism educators and administrators in Yunnan were interviewed. The guides' ages range from 22 to 45 years, and their years of being professional tour guides ranging from 2 to 20 years.

Semi-structured in-depth interviews (in either Mandarin or local dialect) were conducted with these 24 participants. They discussed a variety of topics relating to communication strategies with international tourists. Topics include 
perception of identities in intercultural communication, and perceptions of effective communication, and strategies used when communicating with international tourists.

Participant observation was used as an important supplementary tool to overcome reliance on participants' self reports. Guides were observed interacting with international tourists: styles of communication, content of interactions, supervision of tourists, and the influences of contexts on interpretation and relationships. Six groups of 131 tourists (from America, Australia, Sweden, Poland, Britain and Holland) were observed during 13 days of guided tours within Yunnan.

\section{FINDINGS AND DISCUSSIONS}

\section{A. Major Findings}

Findings from the data lead to an argument that, in this intercultural context, ethnic identity is a key component for negotiating effective and appropriate communication. As was previously identified, there are three main aspects of identity, namely professional identity, ethnic identity and personal identity. Not all of these identities are stressed equally by the tour guides interviewed. Rather, ethnic identity is more strongly emphasised and it appears to be a dominating element among the three when communicating with international tourists.

Tour guides agree on the importance of keeping a professional identity. The essential requirements for this are to provide service, to maintain an appropriate relationship and to avoid conflicts with tourists. They do not agree on what aspect is most important in order to be a good professional tour guide. Essentially there is again agreement on the qualities of good tour guides, which include good language competence, knowledge of both tourist and local culture, and attitudes towards the profession. But individuals emphasise different things. Some focus on communicative competence and keeping good relationships with tourists; some focus on delivering a good and comprehensive interpretation of local culture; some emphasise that tour guides have to know how to "zuo ren" (act as a human being); and some emphasise "ren qing wei" (human feeling).

The strongest differences relate to "keeping relationships" and having "ren qing wei". There are different strategies for keeping relationships. The younger tour guides seem to be good at using a variety of "superficial" strategies such as singing, dancing, and telling jokes to make tourists happy. By contrast, the older tour guides emphasise drawing attention to similarities and impressing tourists by their interpretation and their broad knowledge. Both groups are able to make tourists happy.

The concepts of professional identity involving "zuo ren" (acting as a human being), and "ren qing wei" (human feeling) in communication are very Chinese. They are emphasised in Chinese communication theory and practice (Gao \& Ting-Toomey, 1998). It is not surprising that some tour guides raised these as essential qualities of professional tour guides. The younger tour guides were more sentimental and showed their "human feeling" in a lot of ways. They stressed friendly relationships with tourists, and some easily developed "human feeling" with tourists. So they cried at tourists' departure, and were more eager to write back to tourists. Compared with them, the older tour guides seemed to be more sensible. They emphasised that quality service involves good interpretation with abundant deep knowledge, good attitudes to communication and respect for cultural differences.

When talking about professional identities and roles, ethnicity was never far from the surface. This could be in relation to the importance of their metaphorical roles ("windows" of China or Yunnan), or in relation to the importance of providing good information, handling sensitive questions, dispelling prejudices, stereotypes and misinformation, defending national or local honour and selling local products to foreign tourists at a healthy profit. Theorists of intercultural communication, such as Gudykunst \& Kim (1997, p.108) point out that social identity rather than personal identity usually has a greater influence when communicating with strangers. Their definition of social identity includes cultural identity, ethnic identity, gender identity, role identity and age. Since Chinese culture is in many ways a collectivist culture, people focus on interdependent identities such as group, professional and ethnic identities, rather than on the more western notion of independent identities such as personal identity (Ting-Toomey, 1999).

Several inferences could be drawn from conversations with the guides, on the idea of an interdependent identity among tour guides. Data shows that only two interviewees directly mentioned the term "identity" and they used the English term instead of Chinese. One reason for this is that "identity", when translated into Chinese, can have several meanings such as "shen fen" (identity) and "ren tong" (identification) and "shu xing" (distinguished characteristics). In western literature, the more independent identities are often argued in relation to "Who am I?" While in a collective society like China, there is a strong emphasis on "interdependent identity". That is, "Who are you?" or "Who am I?" often involve "Who you are/who am I in relation to others?" (Ting-Toomey, 1999, p.78-79). How to behave oneself is not referring to your own will, but in relation to how to behave in order to satisfy others. This is partially what the concept of "zuo ren" implies (Yi, 2000). That is, one has to behave appropriately in relations to others.

It is noteworthy that the issue of ethnic identity rather than personal identity is the focus for the older generation of tour guides' criticism of the younger ones. The young are un-Chinese for being money-driven, for having no culturally appropriate internal ethical compass, and because some of them would give up their ethnic identity in order to please tourists and to get money. They give in at the cost of humiliation and the loss of ethnic face. They (allegedly) cheat and bend the truth in communication with tourists. Naturally the younger guides do not agree with these assessments. Their 
own rationales for their strategies are expressed in different terms. They suppress their own wills, and endure humiliation or loss of self-esteem in order to keep a relationship with tourists—-"suppress yourself”, "Don't get yourself in trouble", and "Not worthwhile to do so" are their ways to avoid conflicts and to maintain relationships.

There is a real generational difference here. The older guides think it is inappropriate to claim the purpose of the younger guides is to maintain their professional identity. While this action is right in some way, in the Chinese context, to be "patriotic" and "to have a standpoint" is also advocated as part of professional requirements. Compared with the younger ones, the older tour guides are more able to cope with this situation. They do so not only through their skills, but also through a perception that they should do so; because they believe they should they strive to find an appropriate way to do so. Sometimes they convince tourists by facts, and sometimes they carry on the communication in accordance with a strongly Chinese cultural framework that both upholds and cuts across the service provider basis of their profession.

There are several problems involved in making strong inferences about the relative salience of ethnic and personal identities from the guides' criticisms of their fellow professionals or of their Chinese tourist clients. There is the temptation to over generalise about the intergenerational basis and to exaggerate the effects of rapid change on the older guides' perceptions. The older guides are possibly merely trying to paint themselves in the best colours: they are Chinese, but do not share the negative traits of fellow Chinese. The discussions with the guides indicate that shared culture and language are not absolutely necessary for successful communication, and that tour guides feel that lack of respect for their professional expertise and identity have created problems for good relational communication with their fellow Chinese. This is a reminder of the complex inter-relationships between ethnic, personal and professional identities.

The interviewees' responses show that perception of identity is inter-related with expectations. These expectations include the desire for being accepted in a certain way as well. In addition identity is related to hopes as well as actual self-realisation. Tour guides are seeking appreciation, understanding and respect in their communication with tourists. It is not to be denied that financial benefit is one thing tour guides care about. This is a real aspect of the profession. What should be emphasised is that the negotiation of identity and its related strategies is strongly concerned with one's value system. The feeling of achievement in return affects tour guides' attitudes towards the profession and their feeling of power, which then affect their strategies in communication.

\section{B. A Special Context for Communication}

The tour guides carry on their intercultural communication in a special context characterised as professional, commercialized and Chinese. In this context, values and role requirements affect perceptions and behaviours. Tour guides' perceptions and strategies in intercultural communication are relevant to both these contexts of tourism and culture in modern China.

1. A professional context

The guides have all identified themselves as members of a profession, with its special obligations and constraints on communication. In order to keep their professional identities, guides try to maintain a polite and appropriate customerservice relationship. For professional reasons, most tour guides are prepared to accept the differences and the "cultural baggage" international tourists bring with them. This is perhaps another reason why these English speaking tour guides do not recognise cultural differences as the biggest difficulty in achieving effective and appropriate communication and why it is sometimes more difficult to communicate effectively and appropriately with their own people.

Since there are competing needs and demands on them, guides are faced with choices. Are they oriented to communication in order to get more financial and self-promotional benefit from the communication? Or are they trying to have good communication for the purpose of finishing their task, then be rewarded according to what they have done?

The guides know it is crucial to master a broad range of technical competencies in communication. However, when they analyse what they do, they are describing a style of communication that is extremely subtle and complicated. They essentially have to become experts in a continuously reconstructed and transactional panoply of rapid verbal and nonverbal communication to establish appropriate identities and relationships with many people at once. They are not just transmitting technical knowledge related to the points of interest in the itinerary.

The professional requirements and rituals to some extent restrain how tour guides play their roles. Tour guiding, like other service providing professions, has a strong communicative function (Cohen, 1985; Wu, 1999), but this communication demands knowledge of cultural differences, both general and specific. The effectiveness of this intercultural communication to a large extent contributes to the success or failure of trips. This also gives tour guides the chance to exercise their power in the communication. With these powers comes an ethical dilemma. Should they take advantage of their position and subvert their professional goals by using subterfuges and fabrication to achieve their commercial goals? As was shown in the data, some of the guides allegedly do so, using their knowledge for additional financial rewards. For example, based on their knowledge of cultural differences, they make judgments on what international tourists would be interested in and what products to promote, and which shop to take them to for bigger financial rewards. Then at a certain time, they do market promotion.

On the other side of the ethical ledger, it could be argued that "guiding shopping" is one function that tour guides should perform. Usually tourists like to buy some local products as souvenirs or gifts when they visit a new place, although the purpose of shopping is different from culture to culture (Park, 2000). 
However, what makes the ethical difference between the guides is how much tour guides emphasise this function, and how much they value this function and what strategies they use to perform this function. While to some extent improving the financial return is part of the tour-guiding profession, the bigger commercialised context can make some tour guides exaggerate this function and make "unprofessional" choices when there are conflicts between the professional and commercialisation. And a different balance of these two can change the essence of communication between tour guides and tourists. If guides' expectations are strongly money-oriented, they will employ different skills in their communication to enable them to reach the financial goal, sometimes in face of criticism from clients and even (as has been alleged) at the cost of ethnic identity.

2. A commercialised context

The importance of commercialisation as a contextual influence has been made evident by the different perceptions and strategies of the three generations of tour guides. These differences to some extent reflect broad social changes, which extend to changes in tourism policy and practice.

Between the 1950s and 1980s, when tourism was just established in China, tourism was one government strategy to strengthen friendship with other countries. Then tour guides were government and non-government diplomats. Tourism during that time was not an industry. After the implementation of the Open Door Policy and Deng Xiaoping's advocacy to hasten reform in China, the government began to shift the orientation of tourism towards building an industry (He, 2000).

From 1978, international tourist guides were strictly chosen for political purposes: they were government cadres, they worked for the government, got strictly determined wages, and their behaviours were also modelled on governmental requirements. The values they developed in the environment they were brought up in strictly restrained their professional behaviour and personal conduct.

However, with the demands of social development, more travel services and tour companies were established, and more and more people were involved in the industry. Privatisation was one prominent reform, and the systems for management of tour guides were also reformed. In 1987, qualification examinations for tour guides were conducted. With the market demands, more people become tour guides and part-time and freelance tour guides emerged, giving more freedom for markets to regulate the supply and demand. Some tour guides no longer had monthly wages. Instead their income was based on how much work they did. Some today earn only 300 to 500 RMB yuan in monthly wages as the basic retainer. To survive, they also rely on commissions and kickbacks. On this, a senior guide showed some sympathy to them and called them "sparrows who fly anywhere that has millet".

So a major problem in the industry is regulating the extent to which these tour guides commercialise their communication with tourists. At the beginning, taking commissions and kickbacks was strictly prohibited by the national tourism regulations, but the administrators found it hard to control. Then they made regulations to stop "cheating" and too much shopping in the itinerary. In particular, different key travel agencies try to prevent the unethical practices of some guides who take tourists to shops which offer overpriced, poor quality or fake goods. However, it is hard to control. When advertising was done by word of mouth for tour guiding as a money-producing profession, more people wanted to join and to earn money.

The changing commercial context in turn creates changes in views about acceptable professional behaviour. With the number of both inbound and outbound tourists increasing, some behaviour, such as taking commissions, is gradually being accepted by tourists. The issue is how tour guides make the advertisements and control the groups and how they try to earn money from their communication. When working with international and domestic tourists, who are different in offering support and indicating politeness, tour guides perceive them differently, and the tourists' attitudes are different.

3. A Chinese context

The Chinese context is the third characteristic of the special nature of communication between the tour guides in my study and international tourists. The term "Chinese context" here refers to the location as well as the social and cultural milieu. The context to be described here is that sense of what is perceived as appropriate "Chinese" behaviour by the guides.

As many theorists have pointed out, for example, Gudykunst and Kim (1997), Chen \& Starosta, (1998), "national" level culture exerts a strong influence on the communication of what is desirable and what is expected. So even when interpreting tour guides' communication as a mix of professionalism and commercialisation, it is still very important to look at the context which tour guides inhabit, and the context in which they were socialised.

One of the strongest illustrations is that, when resolving conflicts, the tour guides adopt "avoiding" or "compromising" strategies. In Chinese culture, harmony is highly advocated. Under this value, they avoid saying "No", trying to be polite, to be respectful to others and avoid being aggressive (Chen \& Starosta, 1998; Yi, 2000). This propensity to conflict-avoidance goes beyond the professional ethos of customer service, and is limited only by strongly felt insults to personal-cum-national identity.

Chinese culture also strongly determines the roles that tour guides have to play, some of which would not usually be found in other tour-guiding contexts in other cultures. The propagandist role, although not now so prominently emphasised in the present tourism industry, is still reflected in the requirements to be patriotic and maintaining the four cardinal principles (keeping to the socialist road, up-holding the people's democratic dictatorship, up-holding Marxism- 
Leninism and Mao Zedong's thoughts, and upholding the leadership of Communist Party of China). They are, officially at least, the basic qualities required for tour guides. To abide in public by these principles, tour guides sometimes have to suppress their personal views and echo government positions on major internal and external policies. This is one reason why some questions which are common to tourists from other countries are regarded as sensitive. Some tour guides, especially the novice, dismiss the sensitive questions perfunctorily, shift to other topics, or just say "sorry". Their communication could not be regarded as effective from tourists' perspective. However, from tour guides' perspective, that is an appropriate strategy because to stop the conversation is necessary to keep intact professional and ethnic identities while playing their professional roles well.

A Chinese context unavoidably requires maintaining the traditional values such as maintaining face, having "ren qing wei" (human feelings), showing "guan xin" (concern) and being careful of "zuo ren" (acting as a human being).

"Zuo ren" is a very important concept in Chinese society. If one knows how to "zuo ren", he or she should always show concerns to others, respect others, and consider others at all times. Every Chinese should learn how to "zuo ren" and to prove that "I am a human being" through reaction to others. This is because "self" is embedded in certain relationships with others (Gao \& Ting-Toomey, 1998; Yi, 2000). Therefore in Chinese culture, there is no abstract "identity" but only concrete roles. This is quite different from the western cultures in which one is first of all an "individual". So the concept "zuo ren" stresses the relational meaning with others. In a collectivist culture like Chinese, people always stress, both consciously and subconsciously, the reciprocal relationship with other people. Through these relationships, they feel their goals are achieved, and their expectations are met.

In China people often say "zuo ren nan" (It's difficult to act as a human being). Yi (2000) gives a description of the difficulties in acting as a human being in a Chinese context. As a human being, you cannot control everything yourself. The responsibility is yours, but the rights belong to others. He compares "zuo ren" to dining out in a restaurant. You pay the bill for others and you have to order dishes for others. You are not sure whether "others" will be satisfied or not, and you are not sure whether you are doing the appropriate thing for others. This is the same as in communication. You are always in relation to others, so you have to be careful in communication to meet others' needs appropriately.

Chinese pay attention to relationships and concerns about what other people say about "myself". This partially explains why tour guides are cautious of domestic tourists and also why they care greatly about the relationship with coach drivers. They appreciate the significance of apparently small things such as tourists' offering tour guides bottles of water in hot days, inviting tour guides to sit down for a rest after walking and standing for a long time, and so on. In addition, tourists from southeastern Asian countries tip tour guides well. Tour guides perceive these as signs of respect and appreciation because these are the practices in Chinese culture for appropriate relationships. That is, if you like somebody, you need to show it in one way or another. A good term to describe this is "bao" (reciprocating). If tourists do not like their tour guides, they are not supposed to "pay back" in one way or another. In addition, tour guides feel that their good work has to be confirmed by tourists in one way or another.

If the responses are perceived to be "unjustly" negative, guides usually feel that their "self" has been denied. International tourists are more supportive and polite. So guides give positive responses. In contrast, domestic tourists' negative responses discourage tour guides because these negative opinions deny tour guides' "self".

As an observer of several domestic tour parties, I felt that both guides and tourists were hoping for some shared respect in the interaction, but were unable to reach it. The influence of Chinese culture applies to both tour guides and tourists. As the guides themselves pointed out, domestic tourists' sceptical attitudes towards tour guides lead them to be suspicious about every action of tour guides as potentially deceiving and exploiting them. There is not enough trust between the two, thus mutual disrespect and sometimes disappointment.

In China, a teacher-centred style of teaching has long been dominant. Students' perception of teachers is that teachers are authorities and sources of knowledge who usually give them answers of Yes and No. At least this was the situation when most of the interviewees received their education. A reasonable generalisation can be suggested hat many Chinese people prefer guided tours in which tour guides give explanations and they listen passively. They do not usually prepare or ask questions. In contrast, people from western countries regard learning as a process to arrive at the truth. They are more challenging and critical of what they are learning. In the process of travelling, they are not ready to accept everything tour guides say as truth and are more likely to ask questions. Paradoxically, Chinese guides who are bilingual and culturally aware are able to accept independent, critical inquiry when they understand its cultural roots and perceive its constructive connotations, even though it contradicts a central Chinese tenet of proper teaching and learning. This situational liberation from Chinese transmission-style teaching possibly accentuates the guides' view of domestic tourists as poor students and to interpret their traditionally sanctioned passivity as evidence of uninterest in learning and disrespect for the teacher.

\section{CONCLUSION}

Findings indicate that tour guides' intercultural communications are conducted in a multiple context characterized as professional, Chinese and commercialised. The contextual influences on their communication are in relation to their identities and strategies. They feel that to reach the goal of effective and appropriate communication with international tourists, they have to constantly negotiate their own identity, their relationship with tourists and some uncertain and changing professional and national contexts for tour guiding. In this context, values and role requirements affect 
perceptions and behaviours. Their perceptions and strategies in intercultural communication are relevant to both these contexts of tourism and culture in modern China. Among these, the Chinese context influences tour guides' perceptions, behaviours, and strategies in quite complex and seemingly confusing ways. They actively construct their communication with perceptions from the cultural context in which they were brought up that subconsciously influence their communication through what is traditionally advocated and valued.

\section{REFERENCES}

[1] Cai, L. P., \& Woods, R. H. (1993). China's tourism service failure. The Cornell Hotel and Restaurant Administration Quarterly, 34(4): 30-39.

[2] Chen, G. M., \& Starosta, W. J. (1998). Foundations of intercultural communication. Boston: Allyn and Bacon.

[3] Cohen, E. (1985). The tourist guide: The origins, structure and dynamics of a role. Annals of Tourism Research, (12): 5 - 29.

[4] Gao, G., \& Ting-Toomey, S. (1998). Communicating effectively with the Chinese. Thousand Oaks, London, New Delhi: SAGE Publications.

[5] Gudykunst, W. B., \& Kim, Y. Y. (1997). Communicating with strangers: An approach to intercultural communication: The McGraw-Hill Companies, Inc.

[6] Gudykunst, W. B. (1994). Bridging differences: Effective intergroup communication (2nd ed.). Thousand Oaks, London, New Delhi: SAGE Publications.

[7] He, G. W. (Ed.). (2000). Zhong Guo Lu You Ye Wu Shi Nian (Fifty years of China's tourism development). Beijing: China Tourism Publishing House.

[8] Huang, Y. (2008). A study on intercultural communication of professional tour guides in Yunnan. Kunming: Yunnan People's Publishing House.

[9] Kramsch, C. (2008). Language and culture. Shanghai: Shanghai Foreign Language Education Press.

[10] Park, M. K. (2000). Social and cultural factors influencing tourists' souvenir-purchasing behaviour: A comparative study on Japanese "Omiyage" and Korean "Sunmul". In K. S. K. Chon, T. Inagaki \& T. Ohashi (Eds.), Japanese Tourists: SocioEconomic, Marketing and Psychological Analysis. New York, London, Oxford: The Haworth Hospitality Press.

[11] Ting-Toomey, S. (1999). Communication across Cultures. New York, London: The Guilford Press.

[12] Wu, B. Z., \& He, C. Y. (1999). Scenic Regions in Yunnan. Kunming: Yunnan University Publishing House.

[13] Yi, Z. T. (2000). Xian Hua Zhong Guo Ren (A Talk on the Chinese). Shanghai: Shanghai Arts Publishing House.

Ying Huang was born in Yunnan, China in 1968. She received her M.A. degree in 1997 in Applied Linguistics and her Ph. D degree in 2005 in Intercultural Communication, both from La Trobe University in Melbourne, Australia.

She is currently an associate professor in School of Foreign Languages \& Literature of Yunnan Normal University, China. She has wide research and teaching experience in TESOL and Intercultural Communication, particularly in teaching English majors and tourism students. Some of her selected publications include Intercultural Communication of Professional Tour Guides in Yunnan (Kunming: Yunnan People's Publishing House, 2008); English for Academic Communication in Intercultural Context (Beijing: Science Publishing House, 2009); English for Business and Tourism (Wuhan: Huazhong University of Science and Technology Publishing House, 2009).

Dr. Huang is holding the position as Chair of School Committee of School of Foreign Language \& Literature of Yunnan Normal University. 